\title{
Docência em Tempos de Covid-19: concepções de professores do ensino médio sobre o uso das tecnologias digitais no ensino remoto
}

\author{
Teaching in Times of Covid-19: conceptions of high school teachers on the use of digital \\ technologies in remote education
}

\begin{abstract}
La docencia en tiempos del Covid-19: concepciones de los profesores de secundaria sobre el uso de las tecnologías digitales en la educación remota
\end{abstract}

\author{
José Batista de Souza ${ }^{1}$ \\ Carlos Alberto Vasconcelos ${ }^{2}$
}

\begin{abstract}
Resumo
A docência, seja em qual for a etapa educacional, sempre foi permeada por desafios, exigindo do professor mudança de postura para dar conta das demandas que aparecem em sua prática. Com a pandemia da Covid-19, os desafios aumentaram exponencialmente, o que tem levado professores a se adaptarem a outras formas de trabalho e a terem um olhar diferente para o uso de tecnologias digitais no processo de ensino-aprendizagem. Nesse contexto, o presente trabalho objetiva analisar as concepções de professores do ensino médio acerca do ensino remoto e do uso de tecnologias digitais para levar adiante este ensino. Trata-se de uma pesquisa de abordagem qualitativa, que teve o questionário online como instrumento de coleta de dados. A partir das concepções dos professores, os resultados apontaram que trabalhar remotamente a partir do uso de tecnologias digitais tem sido desafiador, mas proveitoso. Além disso, uma parte significativa dos docentes admitiram que já foram bastante resistentes ao uso de tais tecnologias, mas que compreendem agora a necessidade de aprender a usá-las com fins pedagógicos.
\end{abstract}

alavras-chave: Docência; Processo de ensino-aprendizagem; Pandemia; Tecnologias

\begin{abstract}
Teaching, whatever the educational stage, has always been permeated by challenges, requiring a change of attitude from the teacher to meet the demands that appear in his practice. With the Covid-19 pandemic, the challenges have increased exponentially, which has led teachers to adapt to other forms of working and to take a different look at the use of digital technologies in the teaching-learning process. In this context, this work aims to analyze the conceptions of high school teachers about remote teaching and the use of digital technologies to carry out this teaching. This is a qualitative approach research, which used the

\footnotetext{
${ }^{1}$ Mestre em Letras pela Universidade Federal de Sergipe - UFS. Professor das Redes Municipal e Estadual da Bahia e da Faculdade do Nordeste da Bahia. Membro do Grupo de Pesquisa Educação e Contemporaneidade (EDUCON)/UFS, do Grupo de Estudos e Pesquisas em Formação de Professores e Tecnologias da Informação e Comunicação/FOPTIC/UFS, e do Grupo de Estudos e Pesquisas em Educação Paidéia/FANEB. E-mail: batistinhadesouza@gmail.com ORCID: https://orcid.org/0000-0001-9722-8818

${ }^{2}$ Professor da Universidade Federal de Sergipe - UFS - Programa de Pós-Graduação em Educação (PPGEDUFS); Líder do Grupo de Pesquisa em Formação de Professores e Tecnologias da Informação e Comunicação (FOPTIC - UFS). E-mail: geopedagogia@ yahoo.com.br
}

Revista Devir Educação, Lavras-MG. Edição Especial, p.247-268, Set./2021. 
online questionnaire as a data collection instrument. Based on the teachers' conceptions, the results showed that working remotely using digital technologies has been challenging, but profitable. Furthermore, a significant part of the teachers admitted that they were already quite resistant to the use of such technologies, but that they now understand the need to learn to use them for pedagogical purposes.

Keywords: Teaching; Teaching learning process; Pandemic; Digital technologies.

\section{Resumen}

La docencia, sea cual sea la etapa educativa, siempre ha estado impregnada de desafíos, requiriendo un cambio de actitud por parte del docente para atender las exigencias que aparecen en su práctica. Con la pandemia de Covid-19, los desafíos se han incrementado exponencialmente, lo que ha llevado a los docentes a adaptarse a otras formas de trabajo y a dar una mirada diferente al uso de las tecnologías digitales en el proceso de enseñanzaaprendizaje. En este contexto, este trabajo tiene como objetivo analizar las concepciones de los docentes de secundaria sobre la enseñanza a distancia y el uso de las tecnologías digitales para llevar a cabo esta docencia. Se trata de una investigación de enfoque cualitativo, que utilizó el cuestionario en línea como instrumento de recopilación de datos. Según las concepciones de los profesores, los resultados mostraron que trabajar de forma remota utilizando tecnologías digitales ha sido un desafío, pero fructífero. Además, una parte importante de los profesores admitió que ya eran bastante resistentes al uso de dichas tecnologías, pero que ahora comprenden la necesidad de aprender a utilizarlas con fines pedagógicos.

Palabras clave: Docencia; Proceso de enseñanza-aprendizaje; Pandemia; Tecnologías digitales.

\section{Introdução}

Desde que surgiu em Wuhan, na China, no final de 2019, a pandemia da Covid-19 3 transformou o mundo e a forma de as pessoas se relacionarem, exigindo delas estratégias de adaptação para continuar com suas atividades pessoais e/ou profissionais. No âmbito educacional, a necessidade de distanciamento social fez com que as relações entre professores e alunos passassem a acontecer a distância, via interfaces digitais, o que exigiu desses atores do processo educativo se abrirem a novas possibilidades.

Saíram de cena tecnologias clássicas (quadro de giz, piloto, televisão, retroprojetor, entre outras), para dar vez às tecnologias digitais (whatsapp, google meet, google classroom, jamboard, kahoot, canva, entre outras), muitas delas desconhecidas no contexto educacional,

\footnotetext{
${ }^{3}$ Nesse trabalho, optamos pela expressão pandemia da Covid-19, no entanto, em citações, pode aparecer pandemia de Covid-19, por se tratar da escolha dos autores, razão pela qual não padronizamos a expressão.
} 
mas com um grande potencial para a dinamização das aulas, tanto agora, com a pandemia, quanto em momentos não pandêmicos, tendo em vista que num mundo interconectado como o atual não podemos deixar de aproveitar o potencial dessas tecnologias para inovar as aulas e nos aproximarmos mais dos alunos que fazem parte da geração digital.

Mas, sair de uma pedagogia pautada na aula expositiva, marcada pela fala do professor (a maior parte do tempo), e a participação do aluno (de vez em quando), e passar a gravar vídeos, pesquisar materiais na internet, adentrar em cursos sobre o uso de tecnologias digitais, ministrar aulas online e ter que encarar as câmeras, não foi uma tarefa fácil para os professores. Muitos ficaram bastante preocupados em como levar adiante o trabalho, devido ao não traquejo com tecnologias digitais, que são fundamentais nesse contexto. Mas, como em outros momentos, o professor precisou se adaptar, não apenas para não deixar os alunos sem estudar, mas também porque foi baixada uma portaria ministerial para que as aulas passassem a acontecer de modo virtual - a portaria $\mathrm{n}^{\circ} 343^{4}$, de 17 de março de 2020, que dispõe sobre a substituição das aulas presenciais por aulas em meios digitais enquanto durar a situação de pandemia do Novo Coronavírus - COVID-19, portaria que foi sendo substituída por outras ao longo do ano, em virtude da incerteza do fim da pandemia.

Pouco a pouco, um formato de ensino diferente passou a figurar no vocabulário social - o ensino remoto, ou ensino remoto emergencial, expressão utilizada para se referir a uma forma de ensino temporária, sem um currículo específico, improvisada, para conter os prejuízos da falta de aulas presenciais. Um formato de ensino que varia de escola para escola, de professor para professor, e que pode ser empregado com ou sem o uso de tecnologias digitais (a famosa entrega de material impresso que ainda acontece em muitas escolas do Brasil). No entanto, vale salientar que as aulas remotas a partir das tecnologias digitais têm um efeito bem maior, tendo em vista que há um contato do professor com os alunos, mesmo virtualmente, e há possibilidades de interação e diálogo.

Diante deste cenário, emerge o seguinte questionamento: quais as percepções dos professores do ensino médio, acerca do ensino remoto e do uso de tecnologias digitais para levar adiante este ensino?

\footnotetext{
4 Disponível em: http://www.planalto.gov.br/CCIVIL_03/Portaria/PRT/Portaria\%20n\%C2\%BA\%20343-20mec.htm. Acesso em 17 de junho de 2021.
} 


\section{OO DEVIR EDUCAÇÃO \\ ISSN: 2526-849X}

Com base neste questionamento, o objetivo deste trabalho é analisar as percepções de professores do ensino médio acerca do ensino remoto e do uso de tecnologias digitais para levar adiante este ensino.

Metodologicamente, o trabalho adota uma pesquisa de abordagem qualitativa, tendo o questionário como instrumento de coleta de dados. Quanto ao aporte teórico utilizado como fonte de análise dos dados, nos apoiamos em Ziede et al. (2016), Zanella e Lima (2017), Moreira e Simões (2017) e Appenzeller et al. (2020).

$\mathrm{Na}$ primeira seção, que sucede esta introdução, trazemos uma discussão sobre a docência em tempos pandêmicos. Na segunda, discutimos sobre as tecnologias digitais a serviço da inovação pedagógica. Na terceira, apresentamos o desenho metodológico e, na quarta, finalizamos com as considerações finais, momento no qual retomamos nosso objetivo de pesquisa e concluímos o trabalho.

\section{A docência em tempos pandêmicos}

Exercitar a docência é algo que, em qualquer tempo, exige do professor determinadas habilidades, afinal, a forma como o processo de ensino-aprendizagem é conduzido, é essencial para o bom andamento do mesmo e para a concretização de resultados positivos. Por isso, o professor precisa estar a cada dia mais atento às mudanças que vão surgindo no contexto socioeducacional, para não sofrer tanto com as adaptações que precisa fazer para levar adiante seu trabalho. Ou seja, “[...] é preciso aprender permanentemente - aprender a aprender porque a vida assim pede" (DEMO, 2008).

Durante o seu fazer pedagógico, o docente vai descobrindo diferentes estratégias e metodologias, as quais vai testando e analisando se são condizentes com a educação de seus alunos e com o momento no qual estão imersos, optando por algumas em detrimento de outras. Nesse sentido, em cada época, diferentes tecnologias são apresentadas ao professor, desde as mais simples, como as usadas rotineiramente no contexto escolar, até as mais "sofisticadas", como as digitais, que conseguem redimensionar as questões espaço-temporais e reunir num mesmo ambiente - o virtual - pessoas que se encontram em diferentes espaços geográficos, a chamada ubiquidade, ou seja, a capacidade de uma mesma pessoa estar em 
vários lugares ao mesmo tempo sem a necessidade de deslocamento físico, graças aos artifícios das tecnologias digitais (SANTAELLA, 2013).

Assim, fazer uso diversificado das tecnologias digitais disponíveis é fundamental quando se almeja levar adiante um ensino de qualidade, marcado pela dinamização, tanto em relação à variedade de recursos tecnológicos utilizados, como também à forma como tais recursos são utilizados, uma vez que eles devem ajudar na concretização de aulas mais atrativas, que rompam com a monotonice e possibilite a participação ativa do aluno principal ator do processo de ensino aprendizagem, tendo em vista que neste processo, ambos ensinam e aprendem (FREIRE, 1996).

Muitos professores, devido a fatores diversos, talvez não tenham se dado conta, antes da pandemia, do quanto o seu trabalho carecia de inovação, de uma nova roupagem, do uso de diferentes tecnologias. Mais do que isso, muitos professores sequer levaram em consideração que seus alunos são de outra geração, aquela no qual o digital é algo marcante. Muitos deles são "nativos digitais", isto é, aqueles que nasceram entre os anos 1990 e 2010, período no qual o contato com aparelhos digitais (smartphones, tablets e notebooks) é algo constante e, mesmo que as desigualdades sociais tenham se acentuado durante a pandemia, revelando que muitos alunos não têm condições básicas de estudar a partir de tecnologias digitais, o direito de estudar e de ser educado de acordo com o seu momento histórico é algo que não pode ser negado, cabendo aos órgãos que gerenciam a educação, através das escolas, criar políticas públicas de acesso às tecnologias digitais, encontrando alternativas para inserir na cultura digital alunos em situação de vulnerabilidade social e econômica. Não podemos esquecer da formação dos professores, pois não adianta trazer as tecnologias para a escola sem preparar o professor para fazer uso delas com seus alunos.

Bons softwares fazem com que professor e aluno se aproximem, porque o professor faz a mediação daquilo que o software pode ajudar a desenvolver com conhecimento [...] a oferta de formações diferenciadas para desenvolver o currículo necessário, um esforço de aperfeiçoamento pode ser um elemento estimulador para o próprio professor, o qual, muitas vezes, se sente abandonado na sua sala de aula (GATTI; SHAW; PEREIRA, 2021, p. 8).

Ou seja, trazer as tecnologias digitais para o contexto educativo é uma forma de professor e aluno se aproximarem e de construírem juntos uma aprendizagem colaborativa, na 
qual o professor não ensina, mas age como mediador da aprendizagem do aluno, orientando-o sobre como prosseguir em seus estudos. Nesse contexto,

O professor tem em mãos uma variedade e uma quantidade enorme de meios, não para facilitar sua tarefa, mas para enriquecer e dar significado àquilo que ensina. As TDs, que permitem acesso aos serviços da rede de Internet, são ferramentas com o potencial de contribuir na construção do conhecimento por meio de pesquisas, nas quais o aluno busca as informações e interage com elas (MODELSKI; AZEREDO; GIRAFFA, 2018, p. 118).

Assim, ao orientar os alunos a fazerem diferentes buscas na internet relativas a conteúdos em estudo, o professor abre espaço para a autonomia do aluno, em ir buscar seu próprio conhecimento, e para o seu protagonismo, tendo em vista que no modelo de educação que se defende nos dias atuais, o aluno deve ser capaz de aprender a partir da pesquisa, tendo o professor como orientador e mediador do processo.

Segundo a Organização das Nações Unidas - ONU, a internet é um direito humano. Além disso, a organização afirmou que desconectar a população da web viola esta política. Sendo assim, num momento em que o mundo é tecnológico e digital, enquanto escola, precisamos empreender esforços para amenizar os problemas que vieram junto à problemática maior - a pandemia da Covid-19, cuidando para que todos os alunos tenham o direito de estudar durante este período, fazendo valer o que prega a ONU em relação ao acesso à internet para toda a população, principalmente as pessoas mais carentes ${ }^{5}$.

Na próxima seção, trazemos uma discussão acerca das tecnologias digitais a serviço da inovação pedagógica, apontando alguns caminhos ao professor para que ele possa sobressairse em meio às dificuldades que o momento pandêmico impõe.

\section{As tecnologias digitais a serviço da inovação pedagógica}

Há muito tempo, se discute sobre o potencial das tecnologias digitais para um ensino inovador, que fuja de um modelo tradicional pautado na sala de aula como o único lócus de ensino e aprendizagem, e o professor como o detentor do saber instituído. Atualmente, devido à pandemia da Covid-19 e à mudança da sala de aula física para a virtual, a necessidade de

\footnotetext{
5 Disponível: http://g1.globo.com/tecnologia/noticia/2011/06/onu-afirma-que-acesso-internet-e-um-direito-
} humano.html. Acesso em 18 de junho de 2021. 


\section{ODEVIR EDUCAÇÃO}

ISSN: 2526-849X

diferentes estratégias e metodologias para a condução do processo educativo se faz urgente, o que por si só já caracteriza uma inovação e convida os professores a deixarem de lado qualquer preconceito acerca das tecnologias digitais e a fazerem uso delas no ensino remoto.

Com a adoção do ensino remoto por milhares de escolas em todo o Brasil, desde 2020, "[...] os professores têm vivido novas formas de ensinar, planejar e avaliar, adequando-se, na velocidade da luz, às imposições resultantes do período da pandemia de Covid-19" (FERREIRA et al., 2020, p. 16). De fato, são tantas mudanças, tantas orientações, que o professor precisa se adaptar rapidamente, sob o risco de ser atropelado pelas demandas que esse tipo de ensino acarreta.

Segundo Modelski, Giraffa e Casartelli (2019, p. 9), “a tecnologia sempre fez parte do cotidiano da escola e o uso pedagógico dependeu do professor. Ou seja, quem cria estratégias, práticas e didáticas para uso de um recurso é o professor". Nesse viés, fica nítido que inovar pedagogicamente não está condicionado ao uso da tecnologia apenas, mas às estratégias metodológicas que o docente faz dela.

A sociedade de hoje é mais hiperativa, hiperconectada e ubíqua, graças às tecnologias digitais da informação e comunicação, que invadiram todos os espaços sociais e mostraram que a vida pode ser menos previsível e cheia de possibilidades, principalmente para aqueles que sabem tirar proveito dos aparatos tecnológicos que se encontram à disposição da sociedade para as mais diversas finalidades (LÉVY, 1999).

A popularização da internet no Brasil está estabelecendo novos processos subjetivos entre os usuários interconectados por redes. As interações proporcionadas pelas redes telemáticas tencionam uma nova forma de ser e de viver em sociedade, reconfigurando o papel de professores e alunos no espaço social virtual (REIS; LUNARDI-MENDES, 2018, p. 299).

No contexto educacional, nunca se usou tanto as tecnologias digitais como hoje. Professores de todos os níveis têm, paulatinamente, compreendido a importância dessas tecnologias para a humanidade e entendido que seu fazer pedagógico carece de inovação, sob o risco de perderem a atenção dos alunos se continuarem a negar o potencial das tecnologias digitais para um ensino mais dinâmico e que oportunize o protagonismo dos mesmos.

A pandemia da Covid-19 veio mostrar que se havia resistência ao uso de tais tecnologias, agora é hora de se despir de qualquer preconceito em relação a elas e aderir ao seu uso, pois os alunos precisam continuar estudando e aprendendo e, essas tecnologias são 
fundamentais para que o professor chegue até o aluno e consiga efetuar qualquer proposta de ensino e aprendizagem. A esse respeito, numa sociedade digitalizada como a atual, é preciso que o professor compreenda a necessidade de inserção dessas tecnologias em sua prática pedagógica, pois “[...] estamos em uma época de grandes transformações, e todos nós temos três opções: temê-las, ignorá-las ou aceitá-las" (JENKINS, 2009, p. 09).

Entretanto, a inovação não está condicionada ao uso das tecnologias digitais, mas à forma como o professor faz uso delas, às diferentes aulas que ele consegue pôr em prática a partir delas, ou seja, a percepção de qual tecnologia é mais adequada para dar conta de determinado conteúdo/tema. Ou seja,

A familiaridade com o uso dos recursos tecnológicos faz com que o professor concentre sua preocupação nas possibilidades didáticas de uso pedagógico e não prioritariamente em questões técnicas relacionadas ao recurso. Isso porque quanto mais fluência o professor desenvolve no que tange ao uso de um recurso, mais tranquilidade ele demonstra para criar possibilidades de uso na sua prática pedagógica (MODELSKI; GIRAFFA; CASARTELLI, 2019, p. 10).

A partir do exposto pelos autores, inovar no ensino, apesar de ser algo almejado por diversos profissionais da educação, não é uma tarefa fácil, requer do professor muita preparação, pesquisa, testagem de metodologias diversas, (re)planejamento de atividades e uso contextualizado das tecnologias digitais. É muito comum, muitos professores, na ingenuidade de suas concepções acerca de tecnologias digitais e ensino, acharem que o simples uso destas como recursos didáticos é sinônimo de inovação, é elemento propiciador de motivação para os alunos, quando na verdade não passa de mero pretexto para a inovação.

Nesse contexto, utilizar um Datashow para explanar determinado conteúdo de forma expositiva, nada tem de inovador, tendo em vista que o professor continua no centro do processo. No entanto, quando o professor orienta os alunos para usar seus notebooks ou smartphones para entrar no Google Earth e realizar determinada atividade ou desafio, o sentido da aprendizagem é totalmente diferente. O aluno aprende fazendo, pesquisando, investigando. Quanto ao professor, restou o papel de mediador, o que realmente se espera deste profissional numa educação contemporânea.

Com a pandemia da Covid-19, até os professores mais resistentes passaram a aderir a tais tecnologias, mergulhando no ciberespaço à procura de vídeos e tutoriais, seja pedindo ajuda a colegas mais aptos com as tecnologias digitais. Em alguns casos, os professores 
pediram ajuda aos próprios alunos que, por pertencerem à geração $\mathrm{Z}$, geralmente apresentam grande facilidade com as interfaces e aplicativos que estão disponíveis.

Em relação à solicitação de ajuda aos colegas, é algo bastante positivo também neste momento, tendo em vista que em todos os momentos da educação os professores "trocaram figurinhas". Agora, mais do nunca, apoiarem uns aos outros é essencial para que o ensino remoto seja menos complexo. A esse respeito, conforme Modelski, Giraffa e Casartelli (2019, p. 12), “[...] o contato com outros colegas permite ao professor conhecer possibilidades e recursos de forma rápida e contextualizada"

Sabemos que "a construção do conhecimento é um processo complexo e que pressupõe a interação com outros saberes em diferentes contextos de aprendizagem" (SANTOS; COSTA, 2018, p. 02). Por isso, valorizar as tecnologias digitais como meios potenciais para o processo de ensino-aprendizagem é algo que o professor não pode perder de vista, uma vez que elas são essenciais para a formação do cidadão deste novo século.

O século XXI é marcado pela ascensão e disseminação das tecnologias digitais da informação e comunicação, e a inovação tem sido uma das palavras mais usadas deste século, devido à compreensão de que, se a sociedade evolui, precisamos acompanhar a evolução por ela proporcionada. Nesse sentido, é preciso que se compreenda o caráter inovador do uso das tecnologias digitais, pois,

[...] a inserção e mesmo a "integração" das tecnologias em qualquer nível de ensino não significa mudanças nas práticas e metodologias. Essa perspectiva aponta os professores como o centro da inovação da prática com o uso de tecnologias, pois a tecnologia (como ferramenta) por si só é vazia. É o professor, com base em sua formação, que tem a possibilidade de propor mudanças metodológicas e transformar o uso de tecnologias numa prática social e cultural (RIEDNER; PISCHETOLA, 2016, p. 38).

De fato, o uso de tecnologias digitais no ensino por si só não garante inovação, nem tampouco coloca o professor como o centro do processo. A inovação está na forma como tais tecnologias são usadas e nos propósitos para os quais foram pensadas. Assim, o professor exerce um papel fundamental na integração das tecnologias digitais no processo de ensinoaprendizagem, planejando suas aulas com o uso dessas tecnologias, mas não apenas como recursos didático-pedagógicos, mas como meio para a construção do conhecimento juntamente com o aluno, verdadeiro centro do processo de ensino e aprendizagem 
(MODELSKI; GIRAFFA; CASARTELLI, 2019; CUNHA, 2016; CERUTTI; BALDO, 2020; DOMINICK; ALVES, 2018).

Assim, a formação docente é primordial nesse contexto, tendo em vista que é essa formação para o uso de tecnologias digitais no ensino, a partir de diferentes cursos de formação continuada em serviço, que proporcionarão ao professor as competências necessárias para educar os estudantes para viverem autonomamente na sociedade da informação, algo que pode ser feito através do ensino híbrido.

\section{Procedimentos Metodológicos}

Neste texto, adotamos a abordagem qualitativa, por ter, conforme Ludke e André (1986, pág. 11) “o ambiente natural como sua fonte direta de dados e o pesquisador como seu principal instrumento. [...] Supõe o contato [...] do pesquisador com o ambiente e a situação que está sendo investigada”. Esta abordagem leva o pesquisador à obtenção de dados descritivos que, "utilizados dentro dos limites de suas especificidades podem dar uma contribuição efetiva para o conhecimento da realidade, ou seja, a busca da construção de teorias e o levantamento de hipóteses" (MINAYO; SANCHES, 1994, p. 239).

Neste caso, um dos pesquisadores integra o quadro docente do Colégio Estadual Professora Luzia Carvalho Silva - lócus da pesquisa, situado na cidade de Antas Bahia e, portanto, tem proximidade profissional com os sujeitos investigados, o que pode favorecer a coleta de dados e o processo investigativo de forma ampla. Ademais, a escolha do lócus da pesquisa se deu porque houve um momento específico - a Jornada Pedagógica Paulo Freire 2021, em que a discussão girou em torno do uso de tecnologias digitais no ensino, o que de imediato trouxe um insight para um dos pesquisadores de que, aquele contexto era propício para uma pesquisa.

No tocante aos objetivos, optamos pela pesquisa exploratória, uma vez que, segundo Gil (2008), esse tipo de pesquisa proporciona ao pesquisador maior familiaridade com o problema em estudo. Trata-se de uma pesquisa que pode envolver levantamento bibliográfico e entrevistas. Nesse caso, não fazemos o uso de entrevistas, mas trabalhamos com o levantamento bibliográfico, para a compreensão de como o assunto em foco tem sido discutido. 


\section{OO DEVIR EDUCAÇÃO}

ISSN: 2526-849X

Em relação aos procedimentos de coleta de dados, adotamos o questionário online do google forms. A técnica de coleta questionário, segundo Gil (1999, p.128), pode ser definida “como a técnica de investigação composta por um número mais ou menos elevado de questões apresentadas por escrito às pessoas, objetivando o conhecimento de opiniões, crenças, sentimentos, interesses, expectativas e situações vivenciadas”. Já em relação à opção pelo questionário do google forms, se deu devido à sua facilidade e adequação ao momento pandêmico. Nesse caso, o questionário respondido pelos professores foi composto por 08 questões, sendo 6 de múltipla escolha, 1 de caixas de verificação e 1 de parágrafo com resposta curta.

\section{Resultados e Discussões}

A fim de analisar as percepções dos professores do Colégio Estadual Professora Luzia Carvalho Silva acerca do uso de tecnologias digitais durante o ensino remoto, após mais de um ano trabalhando no distanciamento social, foram feitas 08 perguntas, que geraram os resultados que seguem. No gráfico 1, trazemos as primeiras concepções dos professores.

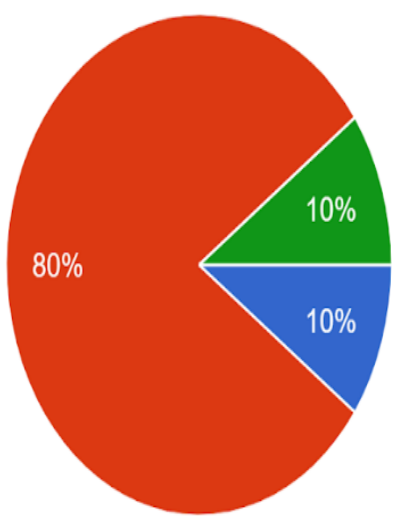

Tem sido tranquilo, pois tenho muita facilidade com o uso de tecnologias digitais e tenho utilizado no ensino.

Tem sido desafiador, pois ainda estou engatinhando no uso dessas tecnologias. Mas tem sido muito prov... Tem sido preocupante, pois não estou conseguindo trabalhar utilizando tecn...

Tem sido tranquilo, pois, apesar de não ter conhecimentos avançados em tec...

Gráfico 1: Uso de tecnologias digitais no ensino remoto Fonte: Dados da pesquisa (2021)

Podemos notar neste gráfico, que a maior parte dos professores, devido às dificuldades inerentes ao uso de tecnologias digitais, algo que raramente acontecia em suas práticas de ensino presencial, considera que trabalhar utilizando tais tecnologias é algo desafiador, algo 


\section{OO DEVIR EDUCAÇÃO \\ ISSN: 2526-849X}

salientado em pesquisas de Ziede et al. (2016, p. 1), quando apontam que "[...] os professores vivenciam desafios constantes para integrar a tecnologia no currículo com propostas que privilegiem a autoria, a cooperação e o trabalho em rede". Os mesmos autores assinalam que "os desafios precisam ser vencidos e para que isto aconteça, os professores precisam refletir, agir, criar, inovar e principalmente perder o medo das TDIC" (ZIEDE et al., p. 8).

Nesse contexto, ficou perceptível que, mesmo com os desafios, os professores reconhecem que tem sido algo proveitoso, provavelmente porque estão descobrindo as potencialidades das tecnologias e percebendo que, em muitos casos, elas ajudam bastante, além de despertarem a atenção dos alunos. Além disso, um dado chama a atenção: $10 \%$ dos respondentes sinalizam ter facilidade com as referidas tecnologias. Isso é algo positivo, pois, tendo alguém na instituição com conhecimentos mais avançados em tecnologias digitais, há a possibilidade de engajamento dos outros professores, a partir de oficinas, por exemplo. Um dado interessante, mas que não apareceu no gráfico, foi a opção tem sido preocupante [...] $\mathrm{O}$ simples fato de nenhum professor ter assinalado essa opção é algo positivo, pois mostra que, apesar dos desafios, os professores estão conseguindo prosseguir seus trabalhos de forma remota.

No gráfico 2, trazemos as concepções dos professores acerca do tópico resistência ao uso de tecnologias digitais no ensino.

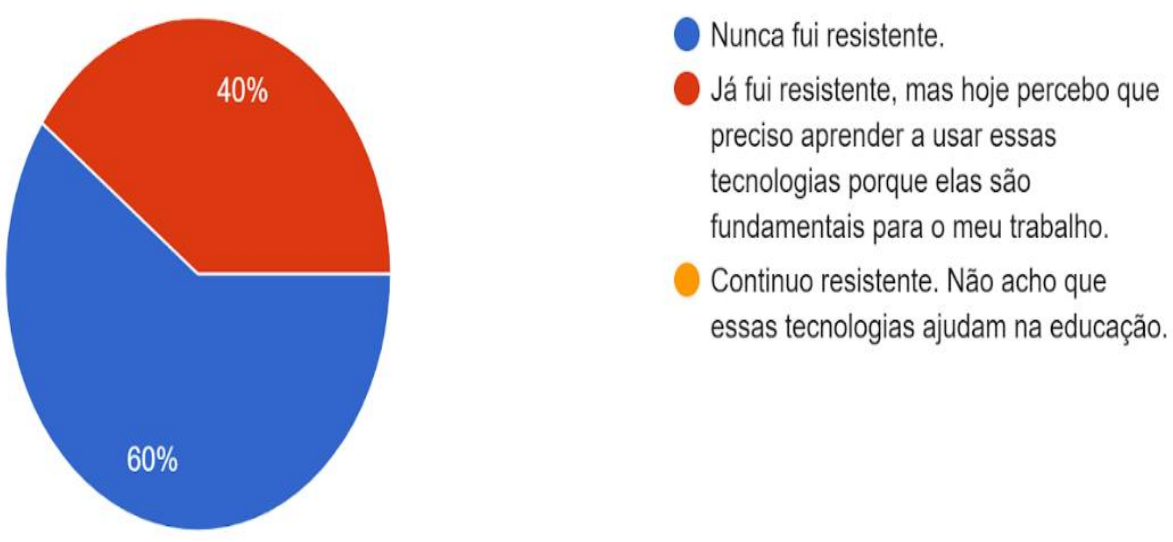

Gráfico 2: Resistência no uso de tecnologias digitais no ensino Fonte: Dados da pesquisa (2021) 
Pelo que o gráfico aponta, a maior parte dos professores disseram que nunca foram resistentes ao uso de tecnologias digitais no ensino, algo que, de diferentes formas nos inquieta, pois, se não eram resistentes, porque não faziam uso pelo menos esporádico dessas tecnologias antes da pandemia? Os $40 \%$ dos professores que assumiram já terem sido resistentes, compreendem a necessidade de aprender a utilizá-las em seu trabalho, algo que pode estimulá-los a um uso mais frequente tanto agora, durante a pandemia, quanto após a pandemia. A esse respeito, enquanto "[...] muitos professores demonstram resistência ao utilizar os recursos tecnológicos, em contrapartida, outros enriquecem suas aulas valendo das ferramentas proporcionadas pelo computador" (ZANELLA; LIMA, 2017, p. 3).

O gráfico 3 apresenta algumas tecnologias digitais utilizadas em 2020 pelos professores respondentes da pesquisa.

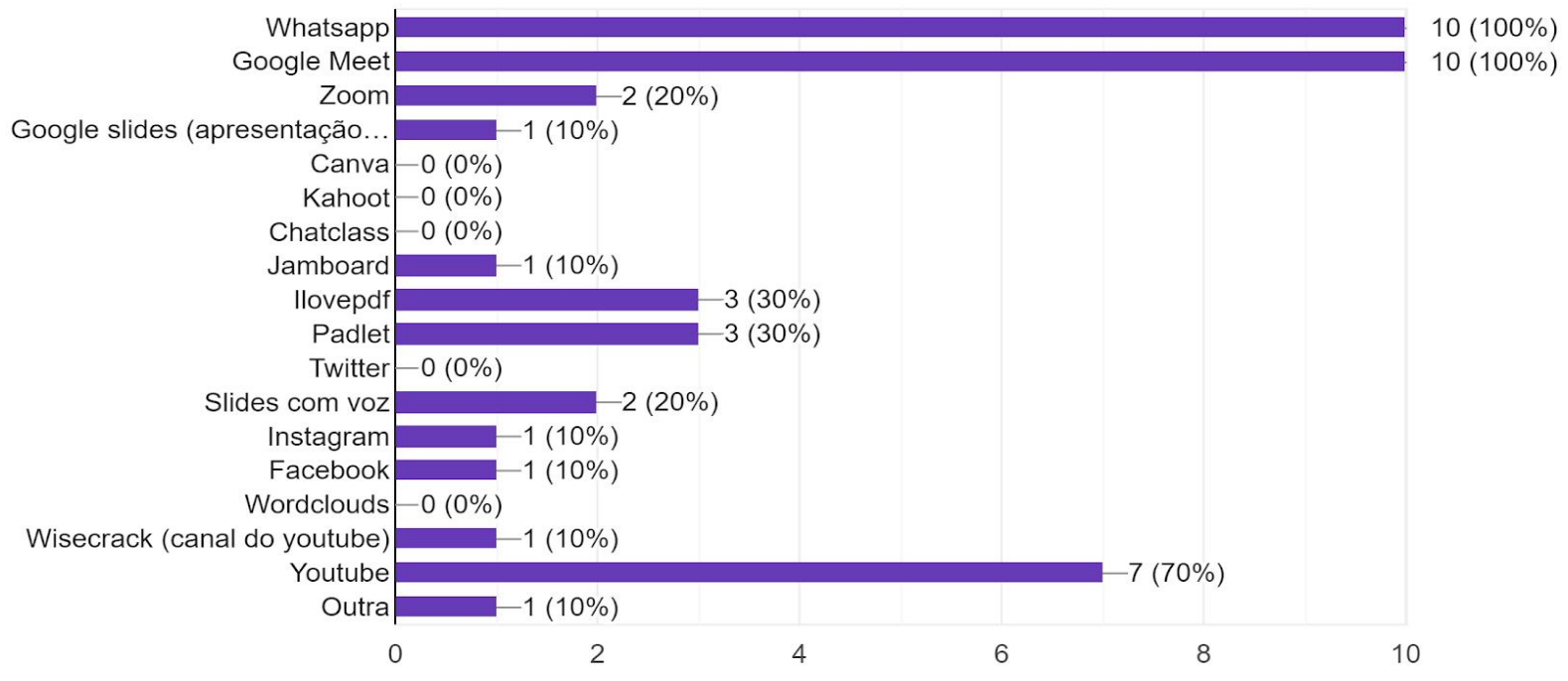

Gráfico 3: Tecnologias digitais utilizadas em 2020 pelos professores

Fonte: Dados da pesquisa (2021)

Questionados sobre as tecnologias digitais utilizadas no ensino remoto em 2020, 100\% dos professores responderam usar o Whatsapp e o Google Meet, além de terem usado outras interfaces com menos frequência. Depreende-se, a partir deste gráfico, que essas duas interfaces são utilizadas pelos professores por causa de sua facilidade de uso, no caso do Whatsapp, e por conta da adesão de muitas escolas ao Google Meet, por ser a forma mais apropriada encontrada no momento para conseguir uma interação mais próxima com os alunos, mesmo a distância. Além disso, conforme Moreira e Simões (2017), o Whatsapp pode 
ser uma interface importante de debates, aulas interativas e de produção intelectual dos estudantes, por isso, a escola não pode ignorá-lo. O Whatsapp está no cotidiano do estudante e, se bem aproveitado, pode ser usado para fins pedagógicos, por isso, “os professores de hoje têm que aprender a se comunicar na língua de seus estudantes" (PRENSKY, 2001, p. 04).

Vale frisar, a partir dos dados apresentados no gráfico, que a variedade de aparatos tecnológicos utilizados pelos professores foi significativa, figurando nomes desconhecidos como Jamboard, Canva, Padlet, Kahoot, entre outros, o que significa que os professores foram à procura de meios digitais para levar adiante o ensino.

Numa outra pergunta, os professores foram questionados sobre a temática tecnologias digitais pagas, cujas respostas vêm na sequência.

Desde que o ensino remoto passou a figurar no vocabulário social, inúmeras plataformas digitais passaram a ser propagandeadas e utilizadas. A procura dos professores por interfaces de fácil manuseio foi algo constante, seja por indicação, seja por curiosidade de buscar na internet por conta própria. Assim que passaram a utilizar algumas interfaces, a exemplo do Padlet $^{6}$, os professores foram percebendo que existe uma versão gratuita, com alguns recursos disponíveis ao usuário, mas também notaram que outras são pagas. O Padlet permite a criação de apenas 5 murais virtuais na versão gratuita, mas é ilimitado na versão paga. Outro exemplo é o $\mathrm{Canva}^{7}$, que oferece dezenas de posts gratuitos, mas também existem alguns com marca d'água, o que significa que o usuário deverá pagar um valor para poder baixá-los. Nesse contexto, e retomando o gráfico, os professores, por unanimidade, não demonstram nenhum interesse nas tecnologias digitais pagas, tendo em vista que há diversas opções gratuitas.

O gráfico 4 traz as concepções dos professores acerca da socialização de diferentes tecnologias digitais durante a Jornada Pedagógica Paulo Freire 2021.

\footnotetext{
${ }^{6}$ É uma ferramenta que permite criar quadros virtuais para organizar a rotina de trabalho, estudos ou de projetos pessoais. $\mathrm{O}$ recurso possui diversos modelos de quadros para criar cronogramas, que podem ser compartilhados com outros usuários e que facilita visualizar as tarefas em equipes de trabalho ou por instituições de ensino. Disponível em: https://www.techtudo.com.br/dicas-e-tutoriais/2020/07/o-que-e-padlet-veja-como-usar-ferramenta-para-criar-quadro virtual.ghtml. Acesso em 19 de junho de 2021.

${ }^{7}$ Lançado em 2013, o Canva é uma ferramenta online que tem a missão de garantir que qualquer pessoa no mundo possa criar qualquer design para publicar em qualquer lugar. Disponível em: https://www.canva.com/pt_br/about/. Acesso em 19 de junho de 2021.
} 


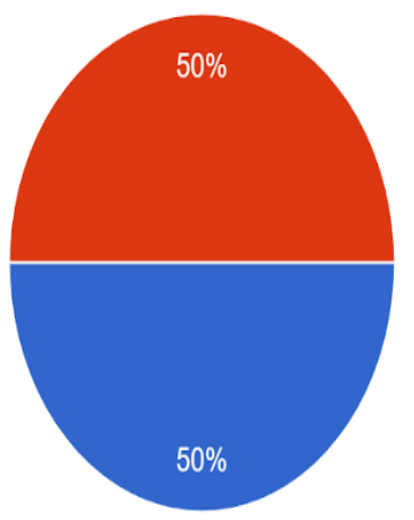

Gráfico 4: Socialização de tecnologias digitais entre os professores Fonte: Dados da pesquisa (2021)
Foi muito interessante. A maioria das ferramentas apresentadas eu desconhecia e acho que posso usar algumas.

Foi interessante, mas a maioria das ferramentas apresentadas eu já conhecia.

Não achei interessante. Achei que é muito dificil fazer uso delas.

Durante a Jornada Pedagógica Paulo Freire, realizada pelo estado da Bahia em 2021, com duração de 5 dias, no Colégio Estadual Professora Luzia Carvalho Silva, a coordenadora pedagógica, lançou um desafio aos professores - apresentar, no dia seguinte, uma tecnologia digital que havia descoberto em 2020 e que ainda estava usando em 2021.

Como um dos pesquisadores é professor da instituição e também participou deste momento, achou interessante colocar no questionário aplicado aos professores algumas questões a respeito deste momento significativo.

Assim, a partir do gráfico, $50 \%$ dos professores avalia a socialização de diferentes tecnologias digitais como muito interessante, principalmente porque a maioria era desconhecida. Algumas chamaram a atenção e alguns professores pretendem experimentá-las. Os 50\% restantes acharam o momento interessante, apesar de já conhecerem a maioria das tecnologias apresentadas.

Essa ideia da coordenadora foi excelente, pois permitiu aos professores o contato com tecnologias desconhecidas até o momento. A socialização entre os professores é importante pois demonstra que momentos de dificuldades como os que se apresentaram durante o ensino remoto, podem ser menos espinhosos quando os professores se ajudam. A esse respeito, uma pesquisa do porvir.org, realizada em 2020, mostra que, com o fechamento das escolas, educadores de todo o Brasil se mobilizaram para trocar experiências e apoiar quem precisa adaptar conteúdos para o ambiente digital ${ }^{8}$.

\footnotetext{
${ }^{8}$ Disponível em: https://porvir.org/professores-lancam-movimento-para-ajudar-colegas-no-uso-de-tecnologia/. Acesso em 19 de junho de 2021.
} 


\section{OO DEVIR EDUCAÇÃO \\ ISSN: 2526-849X}

Em diálogo com o gráfico anterior, o gráfico 5 traz as concepções dos professores acerca das possibilidades de uso das tecnologias socializadas.

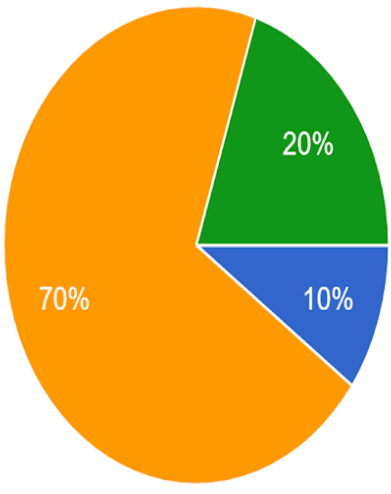

Canva

Padlet

Slide interativo do google

Slide com voz do word

Wisecrack

llovepdf

Nenhuma

Gráfico 5: Possibilidade de uso das tecnologias socializadas

Fonte: Dados da pesquisa (2021)

Como podemos observar no gráfico 5 , foram 8 as diferentes tecnologias socializadas pelos professores durante um momento específico da Jornada Pedagógica Paulo Freire, no entanto, 3 delas foram sinalizadas pelos professores como possibilidades de uso nas aulas: o Canva, com $70 \%$, o Padlet, com $20 \%$ e o Jamboard ${ }^{9}$, com $10 \%$.

O gráfico 6 traz as concepções dos professores acerca do uso de tecnologias digitais durante o ano letivo 2021.

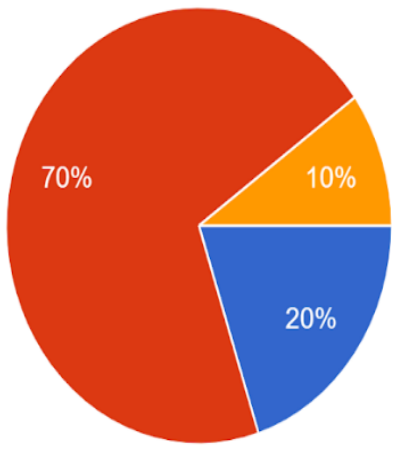

Acho que vamos ter resultados excelentes.

Acho que vamos ter resultados razoáveis, mas significativos.

Acho que os resultados não serão bons pela falta de acesso dos alunos.

\footnotetext{
${ }^{9}$ É um quadro branco digital inteligente que pode ser editado de forma colaborativa com outras pessoas e acessado de qualquer lugar com internet. Trata-se de mais uma das ferramentas oferecidas pelo G Suite for Education, que traz para a sala de aula possibilidades, como: armazenamento de todo conteúdo em nuvem, sincronização com outros aplicativos, diversidade de formatos para transmissão do conhecimento, dentre outros. Disponível em: https://getedu.com.br/2021/01/31/google-jamboard-o-quadro-interativo-para-a-sua-sala-de-aula/. Acesso em 19 de junho de 2021.
} 


\section{OO DEVIR EDUCAÇÃO \\ ISSN: 2526-849X}

Gráfico 6: Expectativas de uso de tecnologias digitais no ano letivo 2021

Fonte: Dados da pesquisa (2021)

Após um ano de ensino remoto mediado por tecnologias digitais, os professores se mostraram entusiasmados para o ano letivo atual a partir do uso de tecnologias, tanto é que a maioria, $70 \%$, acha que os resultados serão razoáveis, mas significativos. Do restante, $20 \%$ acha que os resultados serão excelentes, o que denota uma aceitação do uso das tecnologias digitais e também traquejo com elas. Mas há um percentual de $10 \%$ que acredita que os resultados não serão bons por conta da falta de acesso dos alunos.

Essa concepção é bastante válida no contexto em voga, tendo em vista que, a questão do acesso à internet, de fato, tem sido um entrave em diversas escolas do Brasil para levar o ensino remoto adiante, como demonstram em sua pesquisa Appenzeller et al. (2020, p. 3), ao apontarem que "os principais problemas identificados foram internet instável e/ou acesso exclusivo por redes móveis. As atividades com maior dificuldade de acompanhamento pelos alunos eram transmitidas por webconferências e meetings [...]”.

O gráfico 7 representa as palavra-chave sinalizadas pelos professores ao serem solicitados a indicar 3 palavras que representam a importância das tecnologias digitais para o processo de ensino-aprendizagem.

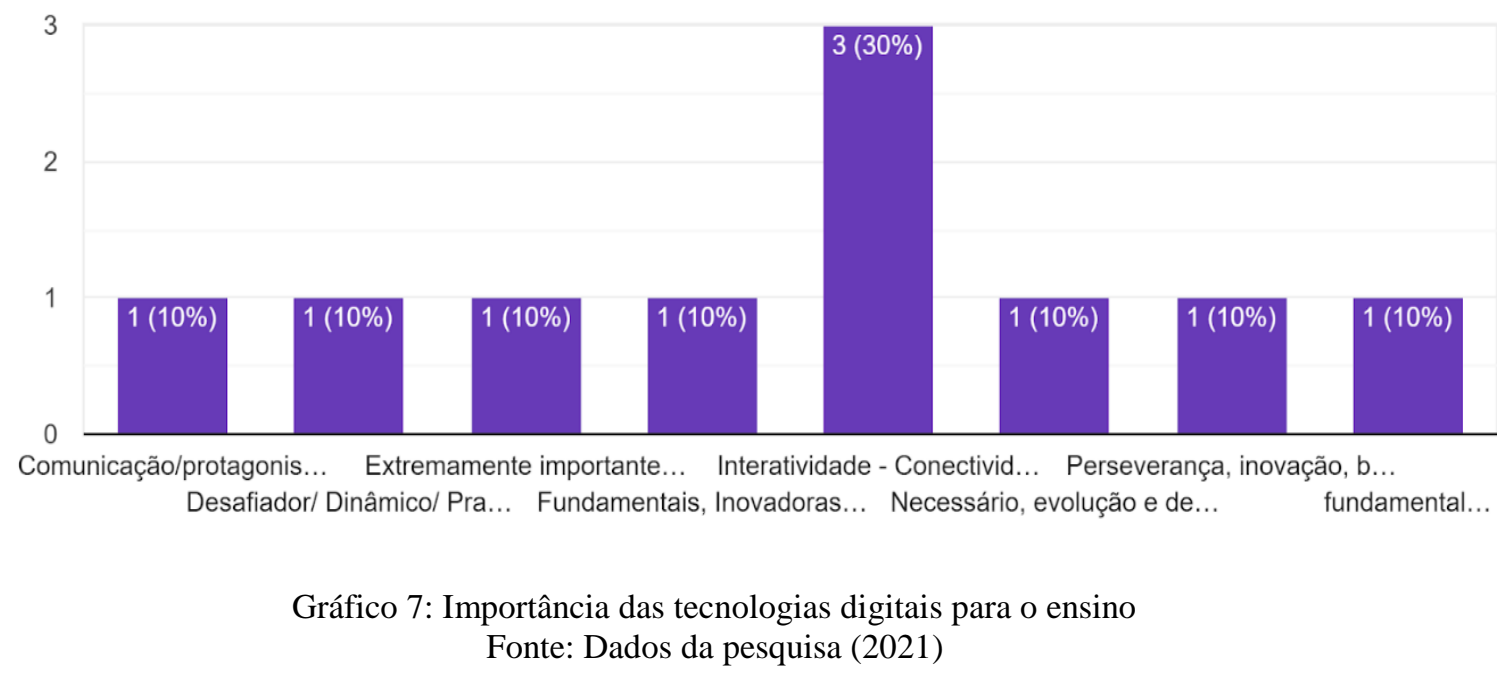

Diante do que foi solicitado, as respostas dadas pelos professores como palavras-chave importantes no contexto do uso de tecnologias digitais apresentaram uma grande variação, 


\section{OD DEVIR EDUCAÇÃO \\ ISSN: 2526-849X}

destacando-se as palavras interatividade, conectividade e inovação. Trabalhar com tecnologias digitais exige interatividade entre docente e discentes, algo possibilitado pela conexão em rede. Quanto à inovação, as tecnologias digitais permitem ao professor inovar em suas aulas, mas isso não significa que as tecnologias, por elas mesmas são a inovação, mas a forma como o professor faz uso delas. Nessa perspectiva,

“[...] escola precisa auxiliar o professor a encontrar uma direção para interagir com o aluno nesse mundo virtual, conectando-se com outras formas de conhecimento e incorporando estratégias com o objetivo de inovar e enriquecer o processo de ensino-aprendizagem de maneira significativa (VASCONCELOS; MENEZES, 2020, p. 115).

Assim, à luz das ideias dos autores, a inovação está na metodologia adotada, tendo as tecnologias digitais como meio para concretizar o que foi pensado. Nesse caso, ao decidir pelo uso de uma dada tecnologia em determinada aula, o professor precisa antes refletir sobre essa tecnologia e perceber nela possibilidades de tornar a aula mais dinâmica. Portanto, a inovação estará na criatividade do professor em fazer uso de uma tecnologia para facilitar a compreensão de um dado conteúdo. O uso descontextualizado de qualquer tecnologia não caracteriza inovação, apenas pretexto.

\section{Considerações Finais}

Neste texto, procuramos analisar as concepções de professores do ensino médio de um colégio estadual da Bahia acerca do uso de tecnologias digitais durante a pandemia, no ensino remoto, com vistas a entender como esses professores têm lidado com os desafios de ensinar remotamente desde que a pandemia da Covid-19 se instalou e impôs a todos o isolamento social e o impedimento de aulas presenciais.

A partir da experiência desses professores, perceptível a partir das análises feitas nos questionários por eles respondidos, notamos que os desafios em relação ao uso de tecnologias digitais no ensino é algo inquietante, assim como ocorre com milhares de professores no Brasil. No entanto, dificuldades à parte, ficou perceptível também que os professores 
compreendem agora, por força da pandemia, a necessidade de adequação e uso de diferentes tecnologias digitais nos processos de ensinar e aprender.

A pesquisa partiu de um insight em um momento pontual do trabalho docente, especificamente durante a Jornada Pedagógica Paulo Freire 2021, um dado bastante relevante, porque o chão da escola é um local propício à pesquisa. Assim, as discussões sobre tecnologias digitais neste momento específico, demonstra que a escola, por mais que se apresente cheia de dificuldades de levar adiante o ensino remoto a partir de aparatos tecnológicos, tem buscado compreender o funcionamento desse tipo de ensino, a fim de encontrar meios eficazes para realizar seu trabalho e garantir aos alunos o direito de continuar estudando e aprendendo, mesmo a distância.

A socialização de experiências dos professores com o uso de diferentes tecnologias digitais e a possibilidade desses professores passarem a fazer uso de algumas das tecnologias apresentadas no ensino remoto é um ponto de suma importância no contexto em voga, tendo em vista que, na escola, as coisas tendem a dar certo quando os professores trabalham em coletividade. Neste período pandêmico, a atitude dos professores em socializar seus conhecimentos tecnológicos com os colegas é um caminho para a mudança de postura na escola e uma luz para que nela os professores não trabalhem cada um por si, mas em colaboração.

Portanto, fazer uso de tecnologias digitais no processo de ensino-aprendizagem em qualquer contexto, seja ele pandêmico ou não, é uma necessidade. Mais do que isso, é uma obrigação do professor, mesmo no ensino presencial, valorizar as potencialidades dessas tecnologias para a dinamização do seu trabalho e também, para respeitar o tempo do aluno que vive neste contexto notadamente tecnológico. Além disso, como já apontou a ONU, a internet é um direito humano, razão pela qual a escola precisa se adequar para oferecer aos seus alunos aulas condizentes com o seu tempo, ou seja, as tecnologias cada vez mais tornamse extensões inerentes ao ser humano.

\section{Referências}

APPENZELLER, Simone et al. Novos tempos, novos desafios: estratégias para equidade de acesso ao ensino remoto emergencial. RBEM - Revista Brasileira de Educação Médica, Rio de Janeiro, v. 44, e0155, p. 1-6, 2020. Disponível em: https://plu.mx/scielo/a/?doi=10.1590/1981-5271v44.supl.1-20200420. Acesso em 20 de junho de 2021. 
CERUTTI, Elisabete; BALDO, Ana Paula. Da ambiência do aluno à prática docente: olhares sobre as tecnologias digitais em sala de aula. EccoS-Ver. Cient., São Paulo, n. 55, p. 1-18, e8349, out./dez. 2020. Disponível em: https://periodicos.uninove.br/eccos/article/view/8349. Acesso em 20 de junho de 2021.

CUNHA, Maria Isabel da. Inovações na educação superior: impactos na prática pedagógica e nos saberes da docência. Em aberto, Brasília, v. 29, n. 97, p. 87-101, set./dez. 2016. Disponível em: http://rbep.inep.gov.br/ojs3/index.php/emaberto/article/view/3172. Acesso em 18 de junho de 2021.

DEMO, Pedro. Habilidades do Século XXI. B. Téc. Senac: a R. Educ. Prof., Rio de Janeiro, v. 34, n.2, maio/ago. 2008. Disponível em: http://www.adventista.edu.br/source/aspedgtc/habilidades-do-sec-XXI.pdf. Acesso em 15 de junho de 2021.

DOMINICK; Rejany dos Santos; ALVES, Walcéa Barreto. Inclusão digital e inovação pedagógica: diálogo necessário. RIAEE - Revista Ibero-Americana de Estudos em Educação, Araraquara, v. 13, n. esp. 2, p. 1334-1358, set. 2018. Disponível em: https://periodicos.fclar.unesp.br/iberoamericana/article/view/11647. Acesso em 15 de junho de 2021.

FERREIRA, Líllian Franciele Silva et al. Considerações sobre a formação docente para atuar online nos tempos da pandemia de Covid-19. Rev. Docência Ens. Sup., Belo Horizonte, v. 10, e024761, 2020. Disponível em: https://periodicos.ufmg.br/index.php/rdes/article/view/24761. Acesso em 22 de junho de 2021.

FREIRE, Paulo. Pedagogia da Autonomia: saberes necessários à prática educativa. São Paulo: Paz e Terra, 1996.

GATTI, Bernadete Angelina; SHAW, Gisele Soares Lemos; PEREIRA, Jocilene Gordiano Lima Tomaz. Perspectivas para formação de professores pós pandemia: um diálogo. Revista Práxis Educacional, Vitória da Conquista, v. 17, n. 45, p. 1-25, abr./jun. 2021. Disponível em: https://periodicos2.uesb.br/index.php/praxis/article/view/8361. Acesso em 23 de junho de 2021.

GIL, Antonio Carlos. Métodos e técnicas de pesquisa social. São Paulo: Atlas, 1999.

GIL, Antonio Carlos. Como elaborar projetos de pesquisa. São Paulo: Atlas, 2008.

JENKINS, Henry. Cultura da convergência. São Paulo: Aleph, 2009.

LÉVY, Pierre. Cibercultura. São Paulo: 34, 1999.

LUDKE, Menga; ANDRÉ, Marli. Pesquisa em Educação: abordagens qualitativas. São Paulo: EPU, 1986.

MINAYO, M. C.; SANCHES, O. Quantitativo-qualitativo: oposição ou complementaridade? Cadernos de Saúde Pública, Rio de Janeiro, v. 9, n. 2, p. 453-478, 2018. Disponível em: https://www.scielo.br/j/csp/a/Bgpmz7T7cNv8K9Hg4J9fJDb/?lang=pt\&format=pdf. Acesso em 16 de junho de 2021. 
MODELSKI, Daiane; AZEREDO, Isabel; Giraffa, Lúcia. Formação Docente: práticas pedagógicas e tecnologias digitais: reflexões ainda necessárias. REPesquiseduca, Santos, v. 10, n. 20, p. 116-133, jan./abr. 2018. Disponível em: https://periodicos.unisantos.br/pesquiseduca/article/view/678. Acesso em 15 de junho de 2021.

MODELSKI, Daiane; GIRAFFA, Lúcia M. M; CASARTELLI, Alam de Oliveira. Tecnologias digitais, formação docente e práticas pedagógicas. Educ. Pesqui., São Paulo, v. 45, e180201, p. 1-17, 2019. Disponível em: https://www.revistas.usp.br/ep/issue/view/11093. Acesso em 12 de junho de 2021.

MOREIRA, Michele Lopes; SIMÕES, Anderson Savio de Medeiros. O uso do whatsapp no ensino de Química. ACTIO, Curitiba, v. 2, n. 3, p. 21-43, out./dez. 2017. Disponível em: https://periodicos.utfpr.edu.br/actio/article/view/6905. Acesso em 18 de junho de 2021.

PRENSKY, Marc. Nativos digitais, imigrantes digitais. De On the Horizon (NCB University Press, v. 9, n. 5, p. 1-6, Out. 2001. Disponível em: https://colegiongeracao.com.br/novageracao/2_intencoes/nativos.pdf. Acesso em 29 de junho de 2021.

REIS, V.; LUNARDI-MENDES, G. M. De iniciantes a vanguardistas: o uso de tecnologias digitais por jovens professores. Holos, Rio Grande do Norte, ano 34, v. 1, p. 297-316, 2018. Disponível em: http://www2.ifrn.edu.br/ojs/index.php/HOLOS/article/view/4867. Acesso em 23 de junho de 2021.

RIEDNER, Daiani Damm Tonetto; PISCHETOLA, Magda. Tecnologias Digitais no Ensino Superior: uma possibilidade de inovação das práticas? Revista Educação, Formação e Tecnologias, Rio de Janeiro, v. 9, n. 2, p. 37-55, 2016. Disponível em: https://revistas.uece.br/index.php/redufor/issue/archive. Acesso em 24 de junho de 2021.

SANTAELLA, Lúcia. Comunicação Ubíqua: representação na cultura e na educação. São Paulo: Paulus, 2013.

SANTOS, V. L. P. dos; COSTA, C. J. de S. A. Docência, formação e inovação: percursos interconectados na configuração do conhecimento pedagógico na educação superior. ETD Educação Temática Digital, Campinas, v. 20, n. 1, p. 210-233, 2018. Disponível em: https://periodicos.sbu.unicamp.br/ojs/index.php/etd/article/view/8649170. Acesso em 20 de junho de 2021.

VASCONCELOS, Carlos Alberto; MENEZES, Rodrigo da Silva. Ensino remoto e utilização de Tecnologias da Informação e Comunicação no contexto da Covid 19. In: AGUILERA, Jorge Gonzaga et al. (Org.). Ciência em foco: volume IV. Nova Xavantina, MT: Pantanal, 2020, v. 4, p. 111-124.

ZANELLA, Brenda Rafaela Devens; LIMA, Maria de Fátima Webber Prado. Refletindo sobre os Fatores de Resistência no Uso das TICs nos Ambientes Escolares. Scientia Cum Industria, Caxias do Sul, v. 5, n. 2, p. 78- 89, 2017. Disponível em: http://www.ucs.br/etc/revistas/index.php/scientiacumindustria/article/viewFile/5284/pdf. Acesso em 21 de junho de 2021. 


\section{OO DEVIR EDUCAÇÃO}

ISSN: 2526-849X

ZIEDE, Mariangela Kraemer Lenz et al. Tecnologias digitais na educação básica: desafios e possiblidades. Revista Renote Novas Tecnologias na Educação, Porto Alegre, v. 14, n. 2, p. 1-10, dez. 2016. Disponível em: https://seer.ufrgs.br/renote/article/view/70692/40129. Acesso em 13 de junho de 2021.

Recebido em: 01/07/21

Aprovado em: 10/08/21

Revista Devir Educação, Lavras-MG. Edição Especial, p.247-268, Set./2021. 